\title{
Measurements of Modulus of Elasticity and Thermal Contraction of Epoxy Impregnated Niobium-Tin and Niobium-Titanium Composites
}

\author{
Ken P. Chow and Gabriel A. Millos \\ Lawrence Berkeley National Laboratory, Berkeley, CA, USA
}

\begin{abstract}
In the high field magnet program at Lawrence Berkeley National Laboratory, accelerator magnet prototypes are designed with epoxy impregnated niobium-tin and niobium-titanium superconductor. Accurate mechanical property values are essential for magnet mechanical design and prediction of conductor performance. Two key mean property values are measured on coil samples: modulus of elasticity (Young's modulus) and mean thermal contraction. Measurements are made in compression and are conducted in three orthogonal directions. Modulus of elasticity measurements are currently conducted at room temperature and the mean thermal contraction is measured from room temperature to liquid nitrogen temperature. Room temperature values are compared with values estimated using the individual coil components.
\end{abstract}

\section{INTRODUCTION}

The superconducting magnet program at Lawrence Berkeley National Laboratory is currently developing prototype common coil accelerator dipole magnets [1], [2] and a short bend magnet (Superbend) for the Advanced Light Source [3]. The first common coil magnets use $\mathrm{Nb}_{3} \mathrm{Sn}$ superconductor in a wind-and-react method. Heat treatment and vacuum epoxy impregnation are two fabrication steps which dominate the processing of the superconductor in these coils. Heat treatment is required to react the superconductor and epoxy impregnation toughens and stiffens the reacted coil. The coil winding geometry is a composite comprised of Rutherford cable, glass sleeve, and epoxy.

The Superbend magnet uses rectangular $\mathrm{NbTi}$ superconductor strands insulated with Formvar and assembled in a "wetwind" process with layers of glass cloth. The coil is a composite comprised of conductor strand, Formvar, glass cloth, and epoxy. We measured two key mean property values for composite samples of both magnets: modulus of elasticity in compression at room temperature and mean thermal contraction. The measurements are compared to values estimated using a rule of mixtures calculation.

\section{SAMPLE FABRICATION}

For the $\mathrm{Nb}_{3} \mathrm{Sn}$ sample, 30 short cable lengths approximately $0.2 \mathrm{~m}$ long are stacked two wide and 15 high

Manuscript received September 15, 1998. This work was performed with the support of the Office of High Energy and Nuclear Physics, United States Department of Energy under contract number DE-AC03-76SF00098. in a stainless steel fixture. To match the processing methods of the actual coil, the cables are sleeved with S-glass sleeving, stacked in the fixture, heat treated in a compressed state, and vacuum epoxy impregnated. Cable ends are welded prior to heat treatment and the cable ends are machined smooth after epoxy impregnation. The sample stacking procedure neglects the effect of winding tension in the coil and only matches the epoxy fraction of the coil straight section (coil ends are generally less tightly packed and have more epoxy after impregnation). The epoxy mix is CTD-101 [4].

The Superbend samples are cut from a $0.14 \mathrm{~m}$ long racetrack coil fabricated using the same method as for the full size magnet coils [3]. The sample ends are cut flat and polished. Figure 1 shows cross sections of the $\mathrm{Nb}_{3} \mathrm{Sn}$ and $\mathrm{NbTi}$ samples and Tables 1 and 2 summarize the composite parameters.

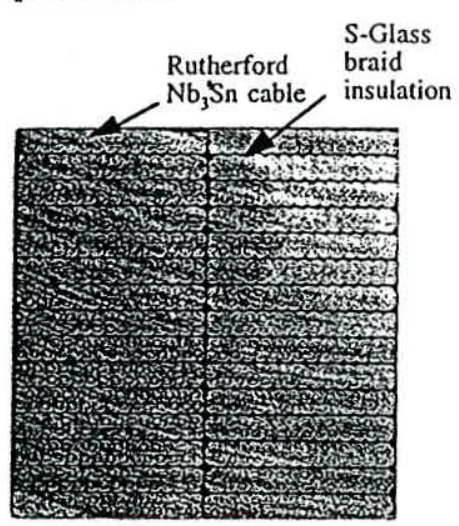

Nb3Sn cable sample

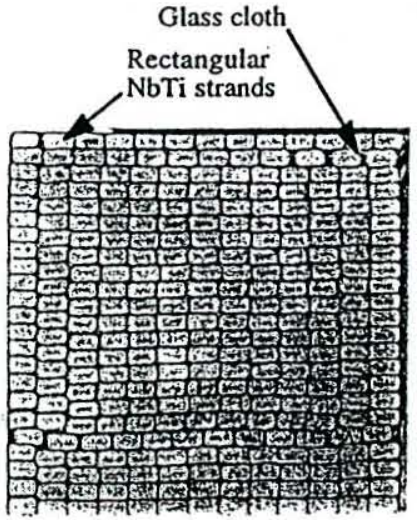

NbTi Superbend sample
Fig. 1. Image of sample cross sections. Horizontal and vertical directions correspond to axial and radial directions, respectively. Tangential direction is normal to page.

\section{Thermal Contraction MEASUREMENT METHOD}

A differential contraction measurement fixture is used to measure mean thermal contraction from room temperature to liquid nitrogen temperature. Figure 2 shows an illustration of the fixture. An aluminum reference cube is fixed to a base and a cantilever arm. Strain gages are mounted on the cantilever arm to measure its deflection and a load screw is used to maintain contact with the test specimen. The fixture measures the differential contraction between the reference cube and a test specimen as both are cooled from room temperature to liquid nitrogen temperature. A change in thermal contraction between the reference and test specimen is measured as a 
TABLE 1

Summary of Properties for $\mathrm{NB}_{3}$ SN CABle COMpostte SAmple

\begin{tabular}{ll}
\hline Conductor material & $\mathrm{Nb}_{3} \mathrm{Sn}$ (from ITER project) \\
Conductor copper fraction & $60 \%$ \\
Conductor strand diameter & $0.805 \mathrm{~mm}$ \\
Number of strands in cable & 30 \\
Cable width & $12.345 \mathrm{~mm}$ \\
Cable thickness & $1.450 \mathrm{~mm}$ \\
Insulation type & S-glass braid \\
Insulation thickness & $0.13 \mathrm{~mm}$ (nominal) \\
Pre-reaction compression & $13.8 \mathrm{MPa}$ \\
\hline
\end{tabular}

TABLE 2

SUMMARY OF PropertIES FOR NBTI SUPERBEND SAMPLE

\begin{tabular}{ll}
\hline Conductor material & $\mathrm{NbTi}$ \\
Conductor copper fraction & $75 \%$ \\
Bare wire size & $0.9 \mathrm{~mm} \times 1.8 \mathrm{~mm}$ \\
Insulation type & PEI, glass cloth between layers \\
Insulated wire size & $1.0 \mathrm{~mm} \times 1.9 \mathrm{~mm}$ \\
Glass insulation thickness & $0.07 \mathrm{~mm}$ (nominal) \\
\hline
\end{tabular}

change in strain gage bridge voltage. If we use the same reference and same initial load (from the load screw), and we assume negligible contraction in the load screw and negligible height reduction due to the load screw, then the difference in thermal contraction between the reference and test specimens may be expressed as

$$
\Delta \varepsilon=K_{1}+K_{2}\left(\frac{V_{b}}{V_{e}}\right)
$$

where $\Delta \varepsilon$ is the thermal contraction difference, $V_{b}$ is the strain gage bridge voltage at $\mathrm{LN}$ temperature, $V_{e}$ is the strain gage excitation voltage at LN temperature, and $K_{1}$ and $K_{2}$ are constants. The two constants in (1) are defined using aluminum 6061 and OFHC copper calibration specimens.

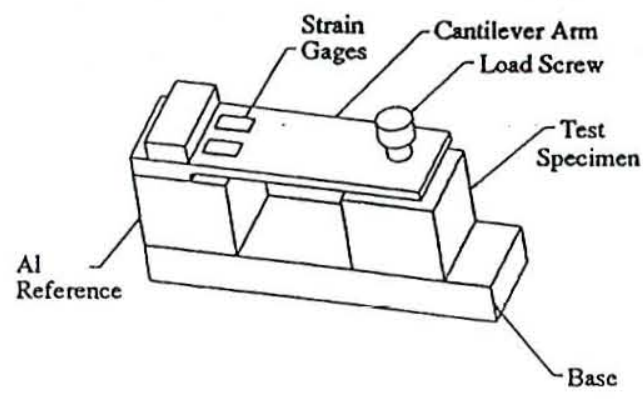

Fig. 2. Sketch of differential thermal contraction measurement fixture.

\section{THERMAL CONTRACTION RESUltS}

The composite coil winding test specimen is a section cut from the sample fabrication fixture. The specimen measures $25.85 \mathrm{~mm}$ in the tangential direction, $25.22 \mathrm{~mm}$ in the radial direction, and $25.18 \mathrm{~mm}$ in the axial direction. The Superbend samples are cut from a small wet-wound racetrack coil. The specimen is a cube measuring $25.4 \mathrm{~mm}$ on each edge.

For the $\mathrm{Nb}_{3} \mathrm{Sn}$ samples, four measurements are taken on the same sample in each direction. Table 3 lists the results. Since the same sample is used for measurements in all directions, cyclic trends due to cooldown effects are not available for radial and axial directions. Reference [5] indicates that there may be cyclic trends in epoxy impregnated $\mathrm{Nb}_{3} \mathrm{Sn}$ coils due to strain relief during cooldown. The large difference in thermal contraction between the first and second cycles (in the tangential direction) indicates that similar cyclic trends may be occurring. No such difference is seen in the radial or axial directions since the specimen has already experienced several cooldown cycles prior to those measurements.

Although the measured results have the same trends as values estimated from a simple rule of mixtures type calculation, the radial direction estimate is almost $9 \%$ higher than the measured values (see Table 3). The rule of mixtures calculation assumes the composite is wound with single strands. The Rutherford cable geometry is significantly different and requires a more complex estimation method for more accurate estimates.

Table 4 summarizes the results for thermal contraction measurements taken on the NbTi Superbend sample in each direction. Unlike the $\mathrm{Nb}_{3} \mathrm{Sn}$ sample, no cyclic behavior is evident. Thermal contraction estimates for the NbTi Superbend sample are of limited comparison value due to the fact that the thermal contraction values for both the Formvar insulation and Stycast epoxy are roughly estimated.

TABLE 3

Mean Thermal Contraction Data for $\mathrm{NB}_{3} \mathrm{Sn}_{\text {Compostte }}$ $295 \mathrm{~K}$ To $77 \mathrm{~K}$

\begin{tabular}{cccc}
\hline Cycle & Tangential & Radial & Axial \\
\hline 1 & -0.00229 & -0.00316 & -0.00290 \\
2 & -0.00295 & -0.00353 & -0.00289 \\
3 & -0.00317 & -0.00338 & -0.00320 \\
4 & -0.00313 & -0.00339 & -0.00322 \\
\hline Standard & & & \\
Dev. & $0.000117(0.000408)^{2}$ & 0.000153 & 0.000182 \\
Average & $-0.00289(-0.00308)^{2}$ & -0.00337 & -0.00305 \\
\hline Estimate & -0.00305 & -0.00367 & -0.00305 \\
\hline
\end{tabular}

${ }^{2}$ Excluding first cycle. First cycle in tangential direction is on a virgin sample. First cycles in radial and axial directions is taken after sample has been thermally cycled for tangential direction measurements.

TABLE 4

Mean Thermal Contraction Data for NbTI SUPERbend CompostTe $295 \mathrm{~K}$ TO $77 \mathrm{~K}$

\begin{tabular}{ccccc}
\hline Cycle & Tangential & Radial & Axial \\
\hline 1 & -0.00278 & -0.00445 & & -0.00389 \\
2 & -0.00299 & -0.00431 & -0.00381 \\
3 & -0.00273 & -0.00455 & -0.00374 \\
\hline Standard & & & - & -0.000119. \\
Dev. & 0.000134 & & 0.000071 \\
Average & -0.00283 & -0.00447 & -0.00383 \\
\hline Estimate. & -0.00274 & -0.00437 & & -0.00341 \\
\hline
\end{tabular}




\section{MOdUlus OF ELASTICITY MEASUREMENT METHOD}

The modulus of elasticity measurements are taken in compression. A hydraulic material testing frame loads the sample to a specified value. Linear Variable Differential Transformers (LVDT) measure the displacement of the cross head relative to the sample support fixture. A calibrated stainless steel cylinder placed between the sample and crosshead plate is used to subtract elastic deformation in the tooling.

Samples are compressed by a series of loads and the position of the cross head recorded by the LVDT's. Individual calibration constants convert output voltages into displacements. The sample engineering strain, $\Delta \varepsilon_{s p}$, is calculated between load points using

$$
\Delta \varepsilon_{s p}=\frac{\Delta L_{t o t}-\frac{L_{s s}}{A_{s s} E_{s s}} \Delta P}{L_{s p}}
$$

where $\Delta L_{t o t}$ is the difference in position of the LVDTs, $L_{S S}$ is the length of the stainless steel cylinder, $A_{S S}$ is the crosssectional area of the cylinder, $E_{S S}$ is the measured elastic modulus of the cylinder, $\Delta P$ is the load difference, and $L_{s p}$ is the length of the test specimen. The modulus of elasticity is calculated using Hooke's Law,

$$
E_{s p}=\frac{\Delta \sigma_{s p}}{\Delta \varepsilon_{s p}}
$$

between each load step and averaged to get a final result.

\section{MODULUS OF ELASTICITY RESULTS}

To certify the validity of the measurement method, two test samples were prepared from common materials. Table 5 lists these results. The aluminum sample measured $36.91 \mathrm{~mm} \mathrm{x}$ $31.25 \mathrm{~mm} \times 31.55 \mathrm{~mm}$. The brass sample was $46.69 \mathrm{~mm} \mathrm{x}$ $30.89 \mathrm{~mm} \times 31.16 \mathrm{~mm}$ in size.

The modulus of elasticity measurements for the $\mathrm{Nb}_{3} \mathrm{Sn}$ sample were taken in three orthogonal directions. Data was taken in each direction twice, except for the axial case in which the second measurement was unusable due to material failure. Table 6 shows the results for the $\mathrm{Nb}_{3} \mathrm{Sn}$ composite (same sample as in thermal contraction test).

As in the $\mathrm{Nb}_{3} \mathrm{Sn}$ sample, the modulus of elasticity was measured in three orthogonal direction for the Superbend 4 composite sample. Only one set of readings was taken for each direction. These results are presented in table 7.

TABLE 5

ElastictTy MOdULUS For AluminUm and Brass TeSt Samples

\begin{tabular}{ccc}
\hline & Aluminum 6061-T6 & Brass \\
\hline Measured & $67.2 \mathrm{GPa}$ & $97.9 \mathrm{GPa}$ \\
\hline Typical Value[6] & $70.3 \mathrm{GPa}$ & $100.0 \mathrm{GPa}$ \\
\hline
\end{tabular}

TABLE 6

ELASTICTYY MODULUS FOR NB33 SN COMPOSTIE

\begin{tabular}{cccc}
\hline Run & Tangential & Radial & Axial \\
\hline 1 & $55.7 \mathrm{GPa}$ & $41.3 \mathrm{GPa}$ & $52.9 \mathrm{GPa}$ \\
2 & $57.8 \mathrm{GPa}$ & $47.4 \mathrm{GPa}$ & $-\mathrm{a}$ \\
\hline Rule of Mixtures & $106.2 \mathrm{GPa}$ & $35.3 \mathrm{GPa}$ & $35.3 \mathrm{GPa}$ \\
\hline
\end{tabular}

${ }^{a}$ Sample yielded during run, data not available.

TABLE 7

ElASTICTYY MOdULUS FOR NBTI SUPERBEND COMPOSTIE

\begin{tabular}{cccc}
\hline Run & Tangential & Radial & Axial \\
\hline 1 & $67.7 \mathrm{GPa}$ & $27.6 \mathrm{GPa}$ & $34.5 \mathrm{GPa}$ \\
\hline Rule of Mixtures & $80.6 \mathrm{GPa}$ & $24.6 \mathrm{GPa}$ & $34.4 \mathrm{GPa}$ \\
\hline
\end{tabular}

\section{CONCLUSIONS}

The technique used to measure thermal contractions is effective for obtaining fast results without requiring a lot of sample fabrication. However, the method is only useful for measuring cyclic behavior in one direction. Multiple samples are required for obtaining cyclic behavior in different directions. The $\mathrm{Nb}_{3} \mathrm{Sn}$ sample seemed to indicate some cyclic behavior but more measurements are required for verification.

Test samples demonstrate the validity of the experimental method for measuring compressive elastic modulus. Furthermore, the values obtained for both composites are reasonable. The modulus in the tangential direction should result in the highest value, as simple composite theory suggests.

For Superbend 4, an elementary construct, the rule of mixtures provides an adequate approximation of both the modulus of elasticity and thermal contraction. In the more complicated structure of the $\mathrm{Nb}_{3} \mathrm{Sn}$ samples, we see much different results. The rule of mixtures provides a much better approximation for thermal contraction than elastic modulus. The Rutherford cable has only a small effect on the mean thermal contraction of the composite since the contraction is governed mostly by volumetric change. However, the cabled geometry is a complicated mechanical system in regards to modulus and requires a more involved analysis for elastic modulus estimates.

\section{REFERENCES}

[1] R. Gupta, "A Common Coil Design for High Field 2-in-1 Accelerator Magnets," Particle Accelerator Conference, Vancouver, Canada, 1997.

[2] K. Chow et al., "Design and Fabrication of Racetrack Coil Accelerator Magnets," European Particle Accelerator Conference, Stockholm, Sweden, June 22-26, 1998.

[3] C. E. Taylor et al., "Test of a High-Field Bend Magnet for the ALS," Applied Superconductivity Conference, Palm Desert, CA, September 1998.

[4] Composites Technology Development, Inc., Boulder, C0 80303, USA.

[5] C. A. Swenson et al, "Measurement of Thermal Contraction Properties for $\mathrm{NbTi}$ and $\mathrm{Nb}_{3} \mathrm{Sn}$ Composites," IEEE Transactions on Applied Superconductivity, Vol. 7. \#2, p. 408, June 1997.

[6] E. Oberg, F. D. Jones, H. L. Horton and H. H. Ryffcl, Machinery's Haindbook 25th Ed. New York, Industrial Press Inc., 1996, p. 383. 